\title{
Preliminary results of the new Norwegian cow index
}

\author{
E. FIMLAND
}

N.R.F., Department of Animal Genetics and Breeding

Agricultural University of Norway, Boks 24, $1432 \stackrel{\circ}{A}$ s, NLH, Norway

The Norwegian cow index of 1978 is described. The formula is standard and is based on information from a) lactation yield per year, b) corresponding herd averages, c) indexes of sire and maternal grandsire, and d. average of indexes of sires included in the herd averages. drawn :

Analysis of data from 242501 cows is also presented. Following conclusion may be

- The cow index used seems to work with an effeciency of 90-95 p. 100 of the theoretical expectation.

- The accuracy of the index of the bulls seems to be lower than expected. These index values have been reduced one unit per year for genetic improvement. This way of adjusting for genetic improvement may not be good enough.

\section{Comparison of methods to extend part lactation records}

\author{
J.A.M. von ARENDONK \\ Department of Animal Breeding, Agricultural University \\ Wageningen, The Netherlands
}

Different methods to predict the milk production in the unknown part of the lactation are compared. Ratio methods are not included, because in many cases the hypothesis on which this method is based doesn't hold. The preliminary results don't show any difference between the multiple regression method, the method using linear regression on the last test month production and the method based on factor analysis.

The two methods based on the incomplete gamma function didn't give as good results as the other three methods.

\section{Genetic parameters of dairy traits of Tyrolian grey}

\author{
R. PAJANOVIC *, R. GRAML and F. PIRCHNER ** \\ * Inst. of Zootechnics and Technology of Livestock Products, \\ Faculty of Agriculture of the University of Sarajevo, \\ Sarajevo, Zagrebacka 18, Jugoslawien \\ ** Lehrstuhl für Tierzucht der Technischen Universität München \\ 8050 Freising-Weihenstephan
}

Genetic parameters were estimated from dairy records of a small natural service population. First lactation yield seems to have a high heritability, probably on account of seasonal calving and thus exclusion of seasonal influences on similarity of relatives. Lactation length shows non-negligeable repeatability and heritability. 